\title{
Investigating the impact of stakeholder management on the implementation of a public access project: The case of Smart Cape
}

\author{
W. Chigona*, D. Roode, N. Nazeer and B. Pinnock \\ Department of Information Systems, University of Cape Town, \\ Private Bag, Rondebosch 7701, Republic of South Africa \\ Wallace.chigona@uct.ac.za
}

Received April 2009

\begin{abstract}
This paper reports on a study that uses the Stakeholder Management Theory to analyse the implementation of a pilot phase of public access project, the Smart Cape Access Initiative, a Cape Town City Council e-government initiative. Data for the study was gathered through in-depth interviews with individuals who were involved, influenced and were affected by the implementation of the pilot project. The study identified the major stakeholders of the project and assessed their importance and influence on the project. Numerous interactions between the stakeholders were identified. It was further noted that no formal stakeholder management was undertaken at the identification and planning stages of the project lifecycle. In addition, results showed that there were missed opportunities for appropriate stakeholder management throughout the project. This study offers insights into agencies involved in planning and running public access projects.
\end{abstract}

*To whom all correspondence should be addressed.

\section{Introduction}

In most developing countries the possibilities which information and communication technologies (ICTs) and Internet in particular offer remain unrealised due to the challenges of low Internet penetration (Basu, 2004). To mitigate against these challenges, governments, in some instances, have resorted to providing public Internet access (e.g. telecenters) to allow citizens to electronically interact with the government agencies. However, the success rate of public access points has generally been low (Chigona \& Licker, 2008). One of the factors which contributes to low usage and low sustainability of public access points has been lack of meaningful stakeholder engagement in formulating and running such projects. What still needs to be explored, however, are the factors which may lead to low stakeholder engagement in such projects. Using a case study approach, this study explores how stakeholder engagement is effected in a public ICT access project and how that may impact on the performance of the project.

This study analyses the stakeholder management during the implementation of the pilot phase of the Smart Cape Access initiative. The Smart Cape Access, an initiative of the Cape Town City Council, was launched in 2002 with the aim of providing free access to ICT to residents of Cape Town (Valentine, 2004). The access points of the initiative were set up in the city council's public libraries. In July 2002, six pilot sites had computers installed which allowed free Internet access to library users (Valentine, 2004). Although the initiative has since been rolled out to most of the libraries in the city, this study focuses only on the pilot phase of the project.
The study uses the Stakeholder Management Theory as a theoretical lens to gain an understanding of the numerous aspects surrounding the implementation of a public Internet access project. The stakeholder framework endeavours to "describe, prescribe, and derive alternatives for corporate governance" to take into consideration and balance the various interests of parties involved directly or indirectly with an organisation (Scholl, 2001:6). Although, originally used for private firms, the theory is still relevant for the public sector projects (Scholl, 2001). Bailur (2006) suggests that stakeholder involvement assists in the successful implementation of ICTs for development projects. The Stakeholder Management framework can be used to better understand the importance of citizens in public access initiatives (Scholl, 2001). The understanding would in turn lead to the development of public access projects that would benefit most stakeholders (Flak \& Rose, 2005) due to stakeholder participation in decision-making. This would also introduce fairness and social justice (Kaler, 2003). In this study we attempt to answer the following questions:

- Who were the stakeholders in the Smart Cape pilot project and what were their roles?

- How did the various stakeholders on the project interact?

- How were the various stakeholders managed?

The study makes practical as well as theoretical contributions. The findings of this study may have implications for organisations funding or implementing public ICT access projects. The findings may lead to increased understanding of how stakeholders in public 
access projects should be managed in order to increase the chances of success. The study further tests the validity and applicability of the theory as a basis of research on public ICT initiatives. This is an important contribution since it has been previously bemoaned that the field of public ICT access lacks theoretical frameworks (Roman, 2003; Bailur, 2006).

The remainder of the paper is organised as follows: section 2 provides a condensed and focused summary of the literature on public access points and the Smart Cape initiative in particular. Section 3 discusses the Stakeholder Management Theory and how it can be applied in studying public initiatives. Section 4 outlines the methodology used in this study. Section 5 contains the results of the data analysis performed on the data collected from the sample. It describes the results under different stakeholder models identified in the literature review. The findings are then analysed and evaluated. Focus is also given to the implications of the findings. Finally, Section 6 discusses the key findings of the study and Section 7 concludes the paper and suggests possible future research.

\section{Background: Public ICT access}

\section{Definitions}

A good entry point into the discussion on the public ICT access project is to talk about the digital divide - ie. the inequalities in access to ICTs amongst different sectors of the society. Besides the divide between countries, the divide may also be evident within a country across different demographic differentiating factors such as gender, urban/rural and levels of education. Due to economic realities in most developing countries, the common way of providing access to the disadvantaged masses is through shared access schemes. Such schemes come in different variations (Roman, 2003; Bailur, 2006). The most common form is the telecenter. In South Africa, a substantial number of public access projects were commissioned under the Universal Service and Access Agency of South Africa previously known as Universal Service Agency (Oyedemi, 2009).

Prior research shows that the public access initiatives are beset with numerous challenges including lack of sustainability and low adoption rate (Colle, 2005; Roman, 2003; Bailur, 2006). Oyedemi (2009) notes that the majority of the initial telecenters established in South Africa either died off due to lack of sustainability or were under-utilised. A similar trend was noted in other parts of the world (Bailur, 2007). Chigona and Mbhele (2008) also note that even government or donor-sponsered public access facilities where users did not pay for usage suffered from low utilisation and consequently did not yield the anticipated effects on the communities.

The reasons most public access points projects fail are rarely of technological nature. In fact, others argue that technological solutions are the simplest component of public access projects (Oyedemim 2009; Roode, et al., 2004). In contrast, the people-related issues are often difficult to address. Such issues relate to inter alia training,degree of buy-in,demographic profile of the potential adopters, power and management of the project (Colle, 2005; Warshauer, 2003; Castells, 2000; Roode et al., 2004). One may argue, therefore, that project management techniques which are people-focused are likely to offer a solution to the challenges of low success rate of public access projects. It is for this reason that this study seeks to explore how stakeholder management was executed in a public access project.

\section{The Smart Cape project initiative}

The Smart Cape Access is an initiative of the City of Cape Town aimed at providing free computer access and Internet connectivity to disadvantaged communities in the Cape Metropole. The facilities are located in the public libraries and are available to anyone with city council library membership (library membership is free of charge). The access points serve as an extension to the libraries' source of information.

Infonomics (2003) evaluated the success of the pilot initiative and determined the value of rolling out the initiative by assessing the views and opinions of various stakeholders. The Infonomics (2003) report and other secondary literature provided an initial indication of the stakeholders involved in the initiative i.e.

- $\quad$ City of Cape Town officials

- $\quad$ Library aministrators and staff

- Community volunteers

- $\quad$ Smart Cape uers and non users

Even though the City of Cape Town IT Department considered the initiative a success, other stakeholders such as users and potential users and library staff were not satisfied, especially with the slowness of the Internet access. Previous studies on Smart Cape show that the project suffers from low quality technology as well as low Internet speeds (Chigona \& Licker, 2008). Chigona and Licker (2008) further point out that the low Internet speed had a negative impact on the adoption of the initiative.

\section{Stakeholder management theory}

\section{Background}

According to the Stakeholder Management Theory, a stakeholder for an organisation is any group or individual who can affect or is affected by the achievements of the organisation's objective (Freeman, 1984). The use of the term "stakeholder" as opposed to "interest groups" or "constituencies" is a deliberate contrast to "stockholders" and "shareholders" (Scholl, 2001). Thus, the Stakeholder Theory is an open challenge to the neo-classical economic theories of the firm which focus on the conventional inputoutput model of the firm (Donaldson \& Preston, 1995; Scholl, 2001). The theory takes into consideration the interests of all legitimate stakeholders while acknowledging that the priority of these interests is not always immediately evident (Kaler, 2003). Stakeholders of a firm may include government, investors, political groups, customers, communities, employees, trade associations and suppliers. 
The Stakeholder Management Theory is categorised into normative, descriptive and instrumental theories (Donaldson \& Preston, 1995; Scholl, 2001). The Descriptive Stakeholder Theory focuses on describing how organisations manage or interact with stakeholders.The Normative Stakeholder Theory prescribes how organisations should treat their stakeholders. In other words, the normative aspect of the theory deals with the ethical question of the necessity of not privileging shareholders over the other stakeholders. The Instrumental Stakeholder Theory claims that paying attention to stakeholders impacts on the achievements of other co-operate goals (Hillman \& Keim, 2001; Kaler, 2003) i.e. "if you want to maximize shareholder value, you should pay attention to key stakeholders" (Freeman, 1999). The three theories "are not discrete, ... [r]ather they are nested within each other" (Kaler, 2003:73).

It is argued, therefore, that taking into account interests of stakeholders can be justified based on ethical grounds - i.e. it is the right thing to do (Kaler, 2003). Maitland (2001:130) argues that stakeholder management allows for an equitable distribution of the benefits of an organisation. It has also been argued that stakeholder management may lead to business success since it creates customer loyalty as well as reducing the staff turnover rate (Hillman \& Keim, 2001)

The Stakeholder Management Theory has a number of critics, especially among economists. Milton Friedman (1970), for instance, famously stated that "The social responsibility of business is to increase its profits". The Stakeholder Theory has also drawn criticism from within its own camp as being too theoretical and needing to ground itself in more data (Gioia, 1999). Jones and Wicks (1999) argue for a unified Stakeholder Theory which combines all the separate strands into a single coherent theory. Freeman (1999) and subsequent authors (e.g. Scholl, 2001) have argued that a convergent theory does not exist and that, though theories may have originated from the same source, their prescriptions and implications differ (Scholl, 2001).

\section{Operationalising the stakeholder theory}

In this study we adopted the operationalisation of the theory suggested by Bailur (2006). Bailur's framework, which is depicted in Figure 1, was deemed appropriate to analyse the implementation of the Smart Cape initiative since it provides an integrated view of the related steps for stakeholder management analysis. Based on this framework, Stakeholder Theory can be carried out in three stages:

1. Stakeholder Identification, Stakeholder Behaviour Explanation and Coalition Analysis

2. Stakeholder Management and

3. Concessions/Bargains.

The stages are discussed in turn in the following subsections.

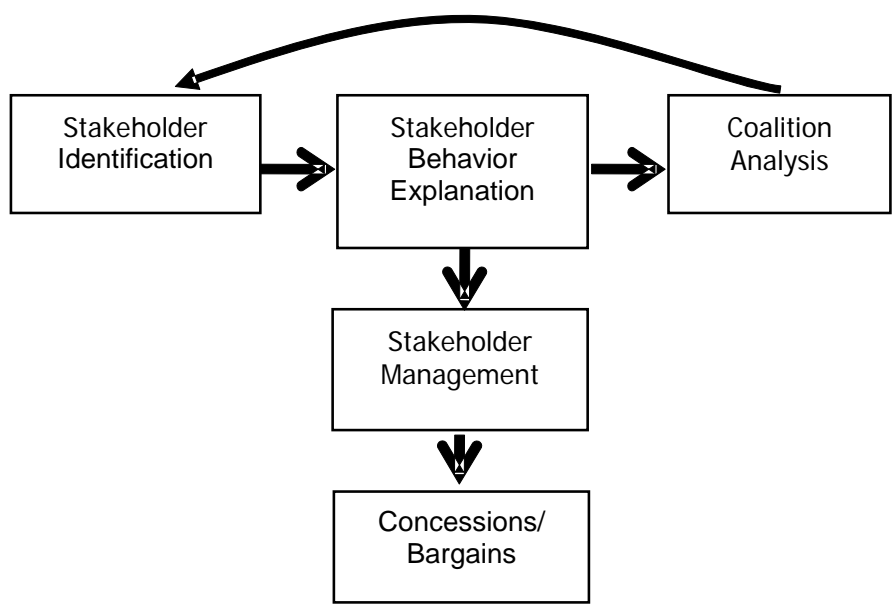

Figure 1: Research framework (adopted from Bailur, 2006)

Stakeholder identification, stakeholder behaviour explanation and coalition analysis

The first stage of the analysis is to identify the stakeholders of a project, their interest, their behaviour and what their history is and then to undertake a coalition analysis - i.e. to understand how they interact with other groups (Freeman, 1984). It should be noted that stakeholders could exert influence (which could be technological, economic, social, political or managerial) in multiple ways and to varying extents (Bailur, 2006). The identification of stakeholders can be conducted by meeting stakeholder groups and validating their self-perceptions by cross-checking against other stakeholder groups (Freeman, 1984).

Stakeholders can be classified along a number of dimensions. They could be classified as primary or secondary (Savage, et al., 1991). Primary stakeholders have formal and economical relationships with the organisation, while secondary stakeholders are not directly related to the organisation despite being able to influence and be influenced by its operation and outcomes (Hillman \& Keim, 2001). Stakeholders may also be classified as environmental or process-related (Atkinson, Waterhouse \& Wells, 1997). Others classify stakeholders as claimants, influencers as well as a combination of both (Kaler, 2002). Freeman (1984) proposed a grid for mapping an organisation's stakeholders based on the categories of power and interest, i.e. claimant and influencer (see Figure 2).

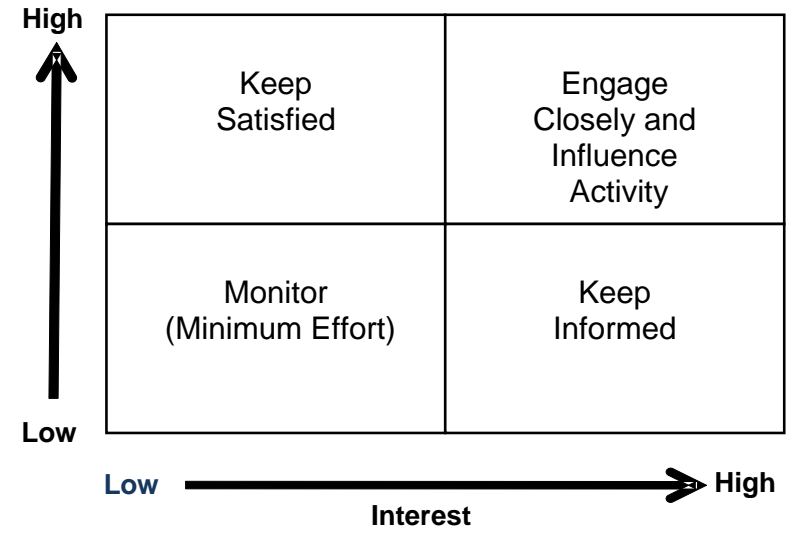

Figure 2: Power and interest grid (Freeman, 1984) 


\section{Concessions/bargains}

One dimension of the Freeman's model relates to the diversity of interests that attracts an external agent to the organisation and makes it a stakeholder. The other dimension relates to the power that agents may have to influence an organisation's behaviour and performance. Stakeholders with high power and interests aligned with the purpose of the project are critical and form the primary audience (Freeman, 1984). These include both the immediate decision-makers and people whose opinion matters. Stakeholders with high interest but low power, or high power but low interest, should be kept informed or satisfied (Freeman, 1984). These would be the secondary audience.

Stakeholders may also be distinguished using the importance versus influence dimensions (Gavin \& Pinder, 1998). Importance relates to how stakeholders' problems, needs and interests are the priority of the intervention, while influence illustrates the power that the stakeholder has (Bailur, 2006). Such information is mapped in a stakeholder importance-influence map. The different components of the stakeholder importance-influence map represent the different groups and sub-groups of stakeholders involved in a project. The stakeholder importance-influence map can thus provide an integrated and comprehensive view of the different groups of stakeholders, their importance, responsibilities and influence on a project. A high importance stakeholder is a stakeholder whose interests, needs and problems are of high priority in a project while a high influence stakeholder is the one with power to influence a project (Bailur, 2006; Clarkson, 1995). One possible weakness of this approach is that the importance and influence ascribed to a particular stakeholder may change throughout the lifecycle of the project.

The general stakeholder identification theory (Mitchell, Agle \& Wood, 1997:854) proposes that classes of stakeholders can be identified by the possession or attributed possession of one or more of these three dimensions: '(1) the stakeholder's power to influence the firm, (2) the legitimacy of the stakeholder's relationship with the firm, and (3) the urgency of the stakeholder's claim on the firm'. By using a combination of stakeholder analysis tools, we aim to provide a stronger basis for proper identification and comprehensive categorisation of stakeholders of Smart Cape Project.

\section{Stakeholder management}

The second stage of the analysis attempts to understand the organisational strategies needed to manage the stakeholders (Bailur, 2006). Gavin and Pinder (1998) as well as Gosling and Edwards (2003) provide a sliding scale of involving stakeholders according to their importance. The scale helps to decide whether to inform, consult, offer partnership or give control to a stakeholder group. The scale can be determined in relation to the different stages of a project's lifecycle, from project identification/analysis to planning, cost/benefit analysis (CBA), implementation, and monitoring and evaluation.
The final stage of the analysis based on the stakeholder framework is the analysis of the set of transactions or bargains used to solve conflicts which arise/arose among stakeholder groups (Freeman, 1984).

\section{Use of the Stakeholder Theory in studies about public sector IT projects}

Even though the Stakeholder Theory has its roots in private sector firms, there is interest in applying it to the public sector (Scholl, 2001). There is benefit to the use of the Stakeholder Theory principles in managerial decisionmaking at an inter- and intra-governmental level, particularly for large-scale IT investments where the risk of failure is high (Scholl, 2001). Cross-sector application of insights of the Stakeholder Theory is fairly straightforward between government-to-government and business-tobusiness scenarios. However, this may not be the case in government-to-citizen scenarios, since government-tocitizen is not the equivalent of business-to-consumer since "[a] consumer is not the equivalent of a citizen" (Scholl, 2001:18).

Several studies have used the Stakeholder Theory to study eGovernment related projects. Example of these are presented in Table 1.

Table 1: Summary of studies using the Stakeholder Theory to study a public project

\begin{tabular}{ll}
\hline Reference & Summary of study \\
\hline Bailur (2006) & $\begin{array}{l}\text { Studied the implementation of a } \\
\text { telecenter in India }\end{array}$ \\
$\begin{array}{l}\text { Flak, Nordheim and } \\
\text { Munkvold (2008) }\end{array}$ & $\begin{array}{l}\text { with dialectic process theory to study } \\
\text { the collaboration between government } \\
\text { departments in an e-government in }\end{array}$ \\
& $\begin{array}{l}\text { Norway } \\
\text { Used the theory to understand the } \\
\text { decision-making process of local } \\
\text { governments in Brazil }\end{array}$ \\
Gomes (2004) & $\begin{array}{l}\text { Studied information sharing amongst } \\
\text { different government departments }\end{array}$ \\
Zhang, Dawes and & Sarkis (2004)
\end{tabular}

Of the studies presented in Table 1, only Bailur's (2006) focused on a public access project. It is on that account that we argue that there is need for more stakeholder studies on public ICT access projects. Bailur (2006) is also interesting from our perspective since it is the only study from the table that used an interpretive approach; this study also employs an interpretive approach.

\section{Research methodology}

Data for the study was gathered mainly through interviews with individuals who were involved, influenced and were affected by the implementation of the Smart Cape pilot project. Reports from studies commissioned by Cape Town City council were used as secondary data.

\section{Sampling of the interview respondents}

Purposive sampling was used to ensure that all the important stakeholder groups were taken into account. Bailur (2006) 
recommends that the stakeholder identification process should ideally be repeated, since subsequent iterations bring up previously unnoticed stakeholders. In this light, the sample was selected in two iterations. The sample for the first iteration consisted of some of the participant groups which formed the sample for a study by Infonomics South Africa (2003). The groups were:

1. City of Cape Town officials

2. Library administrators and staff.

Subsequent to the first iteration, snowball sampling was used for the second iteration. The sample for the second iteration consisted of community volunteers and Smart Cape users and non-users.

\section{Research instrument and data collection}

The interview schedule for the study was based on the research framework (from

Figure 1) and the questions were adapted from Bailur (2006). To ensure clarity and accuracy of the research instrument, the instrument was evaluated by some members of the research team. Subsequent to this, a pilot study was conducted to evaluate the reliability and validity of the questions. Following the reviews, necessary changes were made.

The data was gathered between mid-August and the end of September 2008. As the sample was limited to those who were involved or are/were affected by the implementation of the six pilot sites, a semi-structured interview strategy was used to collect data. The interviews each lasted for approximately 45 minutes each and were carried out at the respondents' preferred location. Two researchers were responsible for each interview: one researcher asked the questions while the other was in charge of recording the interview and taking note of important issues that arose. All the interviews were audio-recorded.

\section{Data analysis technique}

The aim and objectives of the study formed the framework for the analysis and interpretation of the data. Thematic analysis was chosen as the main technique to analyse the data. Thematic analysis provides a more detailed analysis of some aspects of the data collected, relating them directly to the research question and trying to fit them into a predefined coding framework (Braun \& Clarke, 2006).

The first stage of data analysis was mainly to listen to the recorded interviews. We then conceptualised the data by noting the relevant concepts, textual phrases and quotes which related to the major components of the research framework. Following this, the interviews were transcribed into a memo format. Colour-coding was used to facilitate the analysis i.e. the textual phrases were laid out under respective respondents' identification, grouped under each concept in a tabular format and colour-coded. The textual phrases were then analysed and grouped under categories and concepts. Emerging key concepts and categories were identified by studying the results repeatedly and considering possible meanings and how these fitted with the components of the research framework. Finally, all the categories and concepts were combined and were illustrated through the stakeholder analysis tools in order to provide a comprehensive analysis of the implementation of the pilot project. The secondary data was used to validate and support the primary data.

\section{Validity and limitations of the methodology}

Necessary steps were taken to ensure that reliable informants were selected. The data collected from the interviews were analysed with great rigour and attention to detail. Traceability was ensured throughout the data analysis process as the concepts were derived from the original quotations of the respondents. The theory that was developed following the data analysis relates accurately to the data and is considered to be internally consistent. Every effort was made to avoid any preconceptions when mapping the concepts onto the relevant models and maps.

Purposive and snowball sampling were used to obtain sufficient respondents from the two sampling iterations. However, since data for the study was collected seven years after the start of the pilot project, it was difficult to trace most of the people who were part of the project; we ended up with a smaller sample than we had initially intended. This loss was to an extent compensated by the use of the secondary data.

\section{Data analysis and implications}

\section{Stakeholder identification}

We identified 11 groups of stakeholders (see Figure 3). Community volunteers were grouped separately from users because they played a unique role in the libraries and their presence had an impact on the success of the initiative. The libraries are represented by the Head Librarians. Maymoena Ismail, the head of the Steering committee for the project, is identified as a stakeholder in her own right since the other respondents viewed her as personally critical to the success of the project. It should be emphasised that there were two IT Departments in the project, the internal IT Department of the City Council and an external IT department which was contracted specifically for the project. The internal IT Department was taken on as a partner and was in control of some key aspects of the project. Although there is congruence between our findings and the secondary data in terms of stakeholder identification, there is no evidence that the steering committee recruited and managed the stakeholders based on a formal stakeholder identification process. 


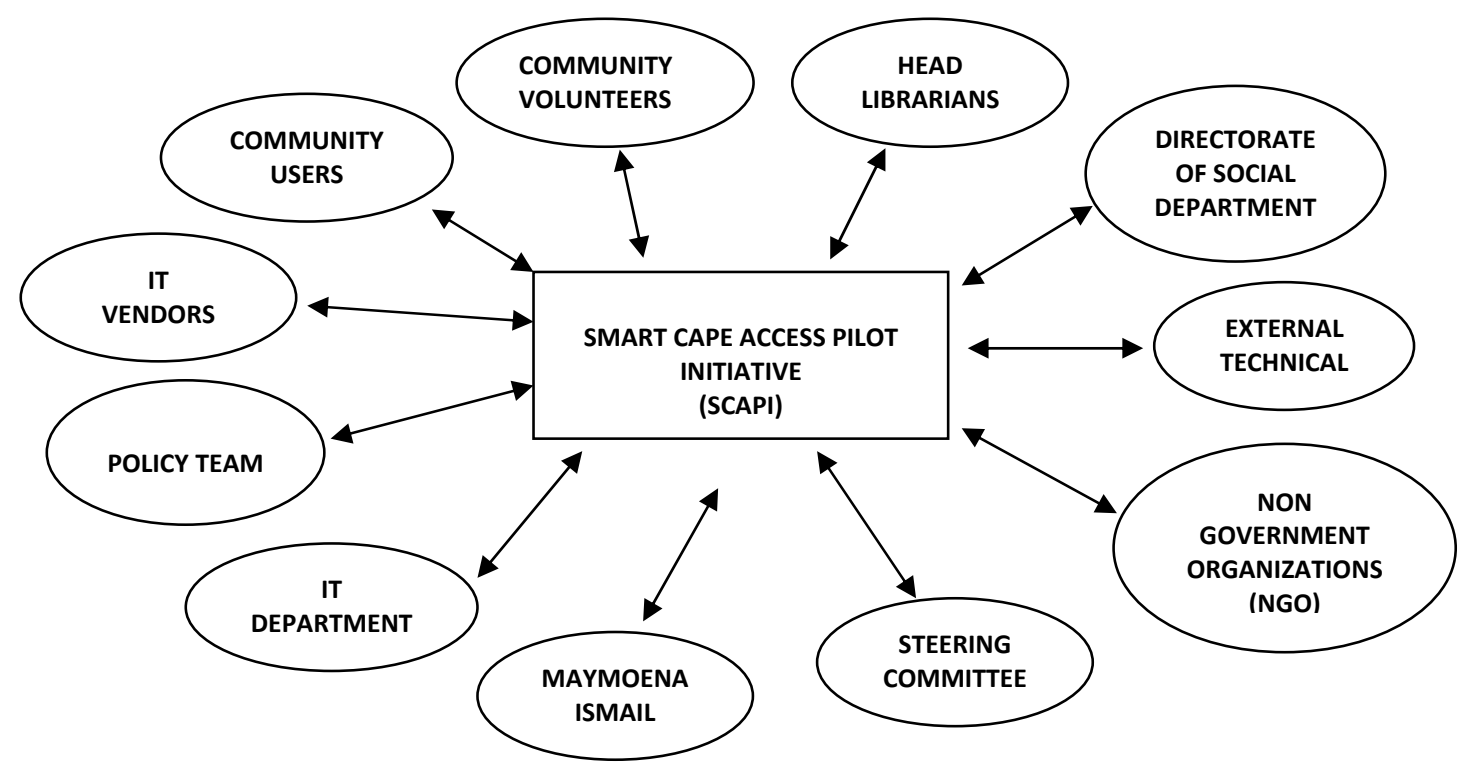

Figure 3: Smart Cape pilot project stakeholder diagram

\section{Stakeholder importance influence}

A stakeholder importance influence map was employed to differentiate stakeholders according to needs, interest, the priority of intervention and influence. The stakeholder importance influence map (Figure 4) shows the extent of influence and how powerful a stakeholder is in a project (Bailur, 2006). We, as a research team, arrived at the ranking of the stakeholder groups through consensus.

Our findings show that the project team did not undertake any analysis of the influence of the stakeholders. The data shows that there was agreement on the high importance/high influence stakeholders. Of concern was the number of stakeholders who were of high importance but exerted low levels of influence. According to the respondents, some important stakeholders such as the community users, volunteers and the Head Librarians were not given an opportunity to influence the project although they were important to the project. Stakeholders were not always consulted on the benefits and purpose of the project and it appears that major decisions were taken unilaterally at certain stages. This could have been one of the factors contributing to the low usage of the facilities. It is also of concern that despite a low importance level, the vendors had a high level of importance.

\section{Stakeholder explanation}

From the data it was evident that certain individuals were more influential than others. There was consensus amongst the respondents on who the most influential people in the project were (i.e. Maymoena Ismail and Mark Neville). The two were described as "assertive”, “...they encouraged innovative ways of serving the public" and "visionary". The data also shows that not all stakeholders were happy with the way the project was coordinated. For example, the "library people were apprehensive" about the project since they were already understaffed and the new project meant more work for them. Again it was noted that at the IT department wasn't happy, with the choice of software adopted for the project. Furthermore, the External Technical Team felt that the IT department took total ownership and credit for the delivery of the project, when, in fact, it was the External Technical Team which was responsible for the delivery of most of the work. It appears that the conflict between these two stakeholders had repercussions on the outcome of the project.

Furthermore, it was noted that the progress of the project might have been negatively affected by poor sharing of knowledge. Sharing of knowledge on the project was not actively promoted, and various stakeholder groups operated, to a large degree, independently of one another. For instance, a respondent stated that: "They [IT] essentially locked my team in a room and kept us away from the rest of them."

\section{Stakeholder coalition analysis}

Our analysis noted five significant coalitions which had an impact on the outcome of the project.

\section{a) Steering committee and Smart Cape users/non-users}

The project steering team went to the six different communities and consulted the residents about the project. However, during the consultations, it was found that the residents did not have the basic resources such as electricity and water, and, therefore, technology was the least of their concerns. Furthermore, the interactions between the project team and the community were not perceived as useful since the residents did not have the capacity to comprehend what the technology entailed and could not meaningfully engage in debate regarding the project. As a result, the people just took it as such without questioning or even pointing out their specific needs. A respondent noted that: "you go and 
have a meeting and you talk about new technology and many of the people don't have running water in their house ... they've never seen the Internet, so how can they give input? So, they just took it even though they didn't know what it was."

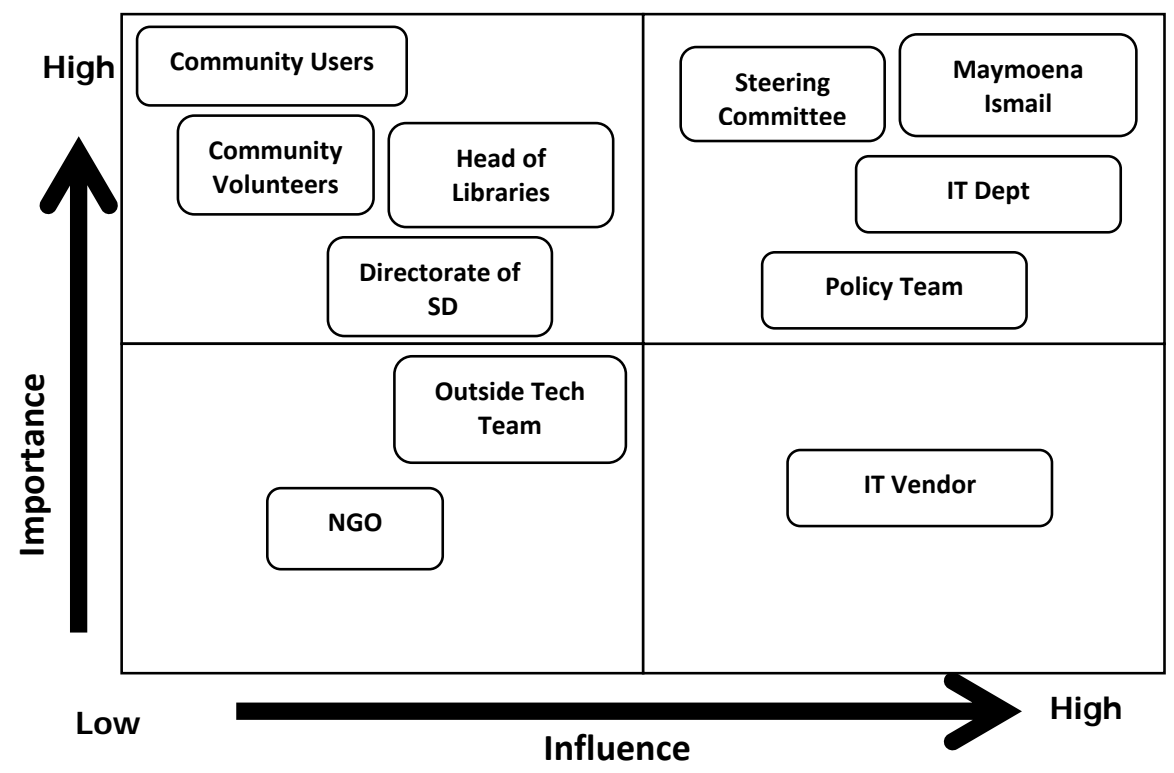

Figure 4: The stakeholder importance influence map

b) External technical team and City of Cape Town IT Department

The relationship between the External Technical Team and the City of Cape Town IT Department was fraught with mistrust. There was poor communication between the two teams. The two teams disagreed on many aspects of the project ranging from who had the right to decide on the technological solution for the project, the choice of software solution as well as the choice of the hardware solution.

The internal IT Department was in charge of the funds allocated for the procurement of technology for the project, they had the last say in any technology decisions, while the external IT Company was appointed to decide on the actual solution. However, the external team felt that the internal IT department made decisions without consulting and brainstorming ideas with them. For instance, even though it could have been the duty of the external team to decide, the internal IT team negotiated with Telkom for a telecommunication solution. Furthermore, according to some respondents, the external IT Company's suggestion to use ADSL was ignored. Instead, the IT Department made a "bad decision" by choosing to go for frame relay which, according to some respondents, resulted in low Internet speeds. The choice of software was also one of the major conflicts between the two teams. One party wanted to use open-source software while the other team preferred propertiary software.

Several conflicts arose between the external IT Company and the City of Cape Town IT Department. Only a few of these conflicts were dealt with appropriately. It can be argued that the outcome of the project could have been better if the steering committee had managed these conflicts more competently.

\section{c) Head librarians and community volunteers}

The relationships between the librarians and the community volunteers was initially good. The librarians were trying to convince the individuals to help them by assisting the Smart Cape users. As was noted by one of the librarians, the volunteers were helpful in assisting the users, thereby reducing the workload of the librarians.

“...he takes a load off our shoulders because we can't still cope seeing to the Smart Cape because there are so many people that don't know how to use PCs and they want us to show them. But it takes time you know you can't just do it in five minutes or so. In actual fact, there should be somebody that mans it - somebody that's paid that mans it all the time."

Despite their critical role in the project, there were no incentives to attract and retain the volunteers due to the unavailability of "funds allocated to the library services for volunteers". The City Council/steering committee did not make provisions for the community volunteers. This led to most of the volunteers resigning .

d) Head librarians and City of Cape Town Steering
Committee

The head librarians were in charge of the projects at local level. However, there was limited interaction between the head librarians and the City of Cape Town IT Department. The communication between the two groups was one way the librarians were told about the project and not given a 
chance to provide their input. One major concern the librarians had which they felt was not taken into account was about staffing. The librarians felt they were already understaffed and that it was unreasonable for the city council to add an extra burden on them without making provisions for extra staffing. According to one head of a library:

"They didn't really ask - we gave our opinion. They wouldn't ask because they knew we would object to being understaffed."

One librarian mentioned that their roles and responsibilities after the implementation were unclear. The respondents also showed that the librarians were not well prepared for the project. However, due to the unavailability of support from the Smart Cape project team, the librarians had to assist users who were having trouble with the computers. One respondent highlighted this::

"They showed us how it worked, yes. But we just had to find our way. Especially the older people that say they want to write a letter but they don't know how, so we have to take our time away from the desk in order to assist those people."

From the responses, it seemed that if the librarians' buy-in had been better managed, the pilot project implementation would have been perceived as a success by most of the stakeholders.

e) Smart Cape users
The data shows a love-hate relationship between users of different age groups. The younger users were generally more skilled than the older users, and the older users depended on the young users for technical assistance. At the same time, the older users felt that the younger users who mainly used the computers to play computer games, were "wasting the computer time". This issue was resolved by the community volunteers who would sometimes "kick out" the youngsters who were perceived to be messing around; the volunteers would also decide to allocate extra time to users who they (the volunteers) perceived to be "busy with serious stuff such as research".

\section{Stakeholder management}

Bailur (2006) advocates a strategy to identify, involve and manage stakeholders based on the sliding scale provided by Gavin and Pinder (1998) and Gosling and Edwards (2003). Depending upon the stage of the project lifecycle, the scale decides to inform, consult, offer partnership or give control to a stakeholder group. Table 2 summarises the results obtained from the interviews as well as the secondary data pertaining to the stakeholder management process based on the sliding scale of management actions against the project phases. The table reflects the "as-was" situation at the end of the pilot project. The table was populated through an iterative process by the whole research team. The inclusion or exclusion of different stakeholders in each of the categories was debated and finalised by consensus.

Table 2: Stakeholder management results

\begin{tabular}{l|l|l|l|l}
\hline & Inform & Consult & Partnership & Control \\
\hline $\begin{array}{l}\text { Identification } \\
\text { /analysis }\end{array}$ & Head Librarians & & $\begin{array}{l}\text { Directorate of Social } \\
\text { Development (SD) } \\
\text { IT Dept }\end{array}$ & Policy Team \\
\hline Planning & Community Users & $\begin{array}{l}\text { IT Vendors } \\
\text { Directorate of SD }\end{array}$ & $\begin{array}{l}\text { External Technical Team } \\
\text { Policy Team }\end{array}$ & Maymoena Ismail \\
\hline CBA and resource allocation & & $\begin{array}{l}\text { IT Vendors } \\
\text { NGOs } \\
\text { Directorate of SD }\end{array}$ & $\begin{array}{l}\text { External Technical Team } \\
\text { IT Dept }\end{array}$ & $\begin{array}{l}\text { Maymoena Ismail } \\
\text { Policy Team }\end{array}$ \\
\hline Implementation & Directorate of SD & $\begin{array}{l}\text { Head Librarians } \\
\text { External Technical Team }\end{array}$ & $\begin{array}{l}\text { IT Dept } \\
\text { Maymoena Ismail }\end{array}$ \\
\hline Monitoring and evaluation & $\begin{array}{l}\text { Head Librarians } \\
\text { Directorate of SD }\end{array}$ & & $\begin{array}{l}\text { NGOs Dept } \\
\text { Community Volunteers }\end{array}$ \\
\hline
\end{tabular}

The respondents indicated that some informing but little consultation happened with libraries and communities. This finding contrasts with Valentine (2004) who indicated that "the process was unique because it reached out to people in small organizations and some of the poorest communities in Cape Town to gain an understanding of their particular experiences and desires as well as to alert them to the issues at stake.” Our findings show that the consultations were not meaningful.

There is some indication that at the planning, CBA and resource allocation stages the IT Department or part of it was not fully involved. For instance, a respondent consistently referred to the exclusion of most of the IT department at these stages. When asked "Who was involved from the IT directorate?" the response was "The CIO.[Chief Informatio Officer] Just the CIO. The whole thing was outsourced to us ...” The data shows that the IT department got more involved in later stages. However, it appears that they enforced some unpopular decisions which negatively impacted on the project.

The role of the internal IT Department was contentious; some even believed that the department was deliberately attempting to sabotage the project. For instance, others felt strongly that the IT department pushed the agenda of 
refurbished machines onto the project as a way to get rid of their old equipment. Regardless of whether that was really the case or not, the lack of involvement of the IT Department personnel (other than the CIO) until late in the project's lifecycle appears to have introduced inefficiencies in the project.

Another interesting aspect of the result relates to community volunteer management. The secondary data indicated the importance of the community volunteers. Infonomics (2003) claims that "There was strong appreciation of the support provided by volunteers at Atlantis, Delft and Grassy Park." Our findings, to the contrary, show that little informing, let alone consulting, was done. It is interesting that the secondary data indicates a passive rather than an active approach to volunteer recruitment and management. For example, Valentine (2004) notes that “...volunteers have emerged at different libraries". Infonomics (2003) uses terms such as "emerged" and "informal" to describe the approach to volunteer management.

Infonomics (2003) indicates that there were differing opinions regarding the use of community volunteers. Some regarded it as increasing skills in communities while others perceived it as exploitation of the community members. Suggestions for training and formal management of community volunteers were put forward, but were not enacted. It could be argued that by simply letting community involvement "evolve", an opportunity to improve the success and sustainability of the project was missed.

Our findings show that, at a macro level, the stakeholder management at each stage was largely appropriate. However, there were areas of issed opportunities for stakeholder management or even inappropriate stakeholder management. The results indicate that there was no formal stakeholder management on both head librarians and the communities at the planning stages of the project. The stakeholder importance influence map (see Figure 4) shows that although both are important stakeholders in terms of the desired outcomes of the project, they held low or no formal influence at these stages of the project. This resulted in a high degree of resistance from libraries. The resistance could possibly have been mitigated through consultation. Management of the community in terms of informing and consulting them, while possibly difficult to achieve, may have yielded better involvement later, especially with regards to community volunteers.

The data also shows that there were possibly inappropriate stakeholder management actions at the CBA and resource allocation as well as implementation stages. There were claims that certain outside vendors relied on their relationships with the IT Department to provide what may have been undue influence on the project direction. Some respondents claim that some of the decisions were based on the fact that some of the vendors "wine and dine the council staff"; others also indicated that some vendors were taken on board simply because they had long relationships with the city council.

\section{Discussion and conclusions}

The findings raise a number of interesting issues in relation to management of stakeholders in a public project. However, due to space limitations, this section will only focus on stakeholder consultation and volunteer management.

\section{Stakeholder consultations}

One interesting finding of this study is the concept of stakeholders consultation in public ICT projects. The benefits of stakeholder consultations include developing acceptance and trust amongst the stakeholders; developing a sense of ownership and a reduction of disputes amongst the stakeholders (Rixon et al., 2007; Cleaver, 1999). Since the project was meant to serve the general public and especially the disadvantaged community, that made them primary stakeholders of high importance in the project. It was necessary, therefore, that they should be consulted. If one were to consider consultation as simply ticking boxes of the groups which have been talked to, one would come to the conclusion that consultation between the steering committee and the community took place. However, in reality, the consultation between the steering committee and the community was not meaningful. Due to low literacy levels amongst the community members, the discussion "went over their heads". The steering committee had in their possession information regarding the social economic situation in the targeted areas, they could therefore have employed consultation techniques which would have been accessible to the people of the literacy level of the target groups.

The interaction between the steering committee and the libraries also raises interesting questions about stakeholder consultation. The librarians were critical to the success of the project, not only because the project was housed in the library, but also because they were tasked to market the project to the general public. However, according to some of the respondents, the library, just like community users were "informed about the project and not consulted". The librarians claim that their concerns of being under-staffed were not taken into account. What would be of interest is to investigate the motivation of the committee's decision. It can be said therefore that in some instances stakeholder consultations are used marely as a political manaouvre and not really meant to get the views of the stakeholders.

\section{Volunteer management}

Most of the respondents affirmed the important role the volunteers played in the project. Their role was particularly important since there was no user training and the libraries were understaffed. However, the results show that the volunteers were not correctly managed and as a result the return from the volunteers was small. The importance of volunteer management has been highlighted by a number of studies (Colle, 2005; Hager \& Brudney, 2004; Hibbert, Piacentini \& Al Dajani, 2003). Without proper management, volunteers burn out easily (Colle, 2005). One of the critical success factors of volunteer management is training the volunteers not only on the technical side, but also on 
customer care (Colle, 2005; Hager \& Brudney, 2004). Hager and Brudney (2004) also argue that training of the paid staff on how to work with the volunteers is critical. Our findings show that in the Smart Project, training was provided to neither the volunteers to enhance their skills nor to the paid staff on how to work with the volunteers. There is also no evidence of official recognition of the volunteers. 


\section{Conclusion}

The primary objective of this study was to investigate how stakeholder management may impact on the success of the public access project. The study was based on the pilot phase of the Smart Cape initiative. The study notes that although the project did not formally employ formal stakeholder management techniques, the steering committee was able to identify most of the stakeholder. The study noted that there were a number of avoidable conflicts which negatively impacted on the project. Most prominent amongst these conflicts was the one between the two IT departments involved in the project. The study also notes that since the project did not apply formal stakeholder management techniques, it missed opportunities such as engaging more actively with important stakeholders such as libraries and community volunteers.

The study focused on the pilot phase of the project. The project has since been introduced into almost all the libraries in the city. It would be of academic interest to investigate how the stakeholder management impacted on the later phases of the project. Chigona and Licker (2008) note that the different libraries had different perceptions of the project. It would be interesting to investigate how stakeholder management was effected at different libraries.

\section{References}

Atkinson, A., Waterhouse, J. \& Wells, R. 1997. 'A stakeholder approach to strategic performance measurement', Sloan Management Review, 38(3):25-37.

Bailur, S. 2006. 'Using stakeholder theory to analyze telecenter projects', Information Technologies and International Development, 3(3):61-80.

Basu, S. 2004. 'E-government and developing countries: An overview', International Review of Law Computers \& Technology, 18(1):109-132.

Bonebright, T., Miner, N., Goldsmith, T. \& Caudell, T. P. 2005. 'Data collection and analysis techniques for evaluating the perceptual qualities of auditory stimuli', TAP, 2(4):505-516.

Braun, V. \& Clarke, V. 2006. 'Using thematic analysis in psychology', Qualitative Research in Psychology, 3:77-101.

Cardona, D. \& Serida-Nishimuara, J. 2006. 'The Peruvian citizen perception and expectation toward the egovernment', The Electronic Tax Payment as a successful eGov Project, 5(10):142-158. Bogoto (Colombia): Univ. Empresa.

Castells, M. 2000. The information age: Economy, society and culture: The network society. Blackwell Publishers.

Checkland, P. 1981. Systems thinking, systems practice. New York: Wiley.
Chigona, W. 2006. 'Should communal computing facilities cohabit with public facilities? The Journal of Community Informatics, 2(3):1-3.

Chigona, W. \& Licker, P. 2008. 'Using diffusion of innovations framework to explain communal computing facilities adoption among the urban poor', Information Technologies and International Development (ITID), 4(3):132.

Chigona, W. \& Mbhele, F. 2008. 'The role of the internet in alleviating social exclusion: The case of the Western Cape Province', The South African Computer Journal, 41:75-85.

Clarkson, M. 1995. 'A stakeholder framework for analyzing and evaluating corporate social performance', Academy of Management Review, 20(1):92-117.

Cleaver, F. 1999. 'Paradoxes of participation: Questioning participatory approaches to development', Journal of International Development, 11(4):597-612.

Colle, R. 2005. 'Memo to telecenter planners', The Electronic Journal on Information Systems in Developing Countries, 21(1):1-13.

Donaldson, T. \& Preston, L. 1995. 'The stakeholder theory of the corporation: Concepts, evidence, and implications', The Academy of Management Review, 20(1):65-91.

Flak, L. \& Rose, J. 2005. 'Stakeholder governance: Adapting stakeholder theory to e-government', Communications of the Association for Information Systems, 16:642-664.

Flak, L., Nordheim, S. \& Munkvold, B. 2007. 'Analyzing stakeholder diversity in G2G efforts: Combining descriptive stakeholder theory and dialectic process theory', e-Service Journal, 6(2):3- 23.

Freeman, R. 1984. Strategic management: A stakeholder approach. Boston: Pitman.

Freeman, E. 1999. 'Divergent stakeholder theory', Academy of Management Review, 24(2):233-236.

Friedman, M. 1970. 'The social responsibility of business is to increase its profits', The New York Times Magazine, September 13, 1970. [online]

URL:http://www.colorado.edu/studentgroups/libertarians/iss ues/friedman-soc-resp-business.html. Accessed July 28, 2008.

Gavin, T. \& Pinder, C. 1998. 'Impact assessment stakeholder analysis'. Manchester: EDIAIS, University of Manchester. [online] URL: http://www.enterpriseimpact.org.uk/pdf/StakeholderAnalysis.pdf. $\quad$ Accessed August 3, 2008.

Gioia, D. 1999. 'Practicability, paradigms, and problems in stakeholder theorizing', Academy of Management Review, 24(2):228-232. 
Gomes, R. 2004. 'Who are the relevant stakeholders to the local government context? Empirical evidences on environmental influences in the decision-making process of English local authorities', Brazilian Administrative Review, 1(1):34-52.

Gosling, L. \& Edwards, M. 2003. Toolkits: A practical guide to planning, monitoring, evaluation and impact assessment. London: Save the Children.

Grande, J., Araujo, C. \& Serna, M. 2002. 'Research on egovernment: A proposal of theoretical framework', Proceedings of the 2002 EGPA Conference on the European Administrative Space, Potsdam, Germany, 4-7 September.

Hager, M \& Brudney, J. 2004. 'Volunteer management practices and retention of volunteers', The Urban Institute. [online] URL: http://www.urban.org/uploadedPdf/411005. Accessed April 7, 2008.

Hibbert, S., Piacentini, M. \& Al Dajan, H. 2003. 'Understanding volunteer motivation for participation in a community-based food cooperative', International Journal of Non-profit and Voluntary Sector Marketing, 8(1):30-42.

Hillman, A. \& Keim, G. 2001. 'Shareholder value, stakeholder management and social issues: What's the bottom line?', Strategic Management Journal, 22:125-139.

Hirschheim, R. \& Klein, H. 1989. 'Four paradigms of information systems development', Communications of the ACM, 32(10):1199-1217.

Infonomic. 2003. 'Evaluation of the Smart Cape Access Pilot Project: A City of Cape Town digital divide initiative.' [online] URL:

http://www.capegateway.gov.za/Text/2003/12/smart_cape_a ccess_project_-_evaluation_final_report.pdf. Accessed July 10, 2008.

Jones, T. \& Wicks, A. 1999. 'Convergent stakeholder theory', The Academy of Management Review, 24(2):206221.

Kaler, J. 2002. 'Morality and strategy in stakeholder identification', Journal of Business Ethics, 39(2):91-99.

Kaler, J. 2003. 'Differentiating stakeholder theories', Journal of Business Ethics, 46:71-83

Levin, A. \& Dingley, A. 2004. 'Opening government information via the Cape Gateway'. [online] URL: http://www.egov4dev.org/transparency/case/cape.shtml.

Accessed August 7, 2008.

Maitland, I. 2001. 'Distributive justice in firms: Do the rules of corporate governance matter?”, Business Ethics Quarterly 11(1):129-143.

Mitchell, R., Agle, B. \& Wood, D. 1997. 'Towards a theory of stakeholder identification and salience: Defining the principle of who and what really counts', Academy of Management Review, 22(4):853-886.
Oyedemi, T. 2009. 'Social inequalities and South African ICT access policy agenda', International Journal of Communication, 2:151 - 168 .

Relyea, H. 2002. 'E-government: Introduction and overview’, Government Information Quarterly, 19(1):9-35.

Rixon, A., Smith, T., McKenzie, B., Sample, R., Scott, P. \& Burn, S. 2007. 'Perspective of the art of facilitation: Delphi Study on natural resource management facilitators', Australian Journal of Environment Management, 14:179191.

Roman, R. 2003. 'Diffusion of innovations as a theoretical framework for telecenters', Information Technologies and International Development, 1(2), 55-68.

Roode, D., Pollock, M., Speight, H. \& Webber, R. 2004. 'It's not the digital divide - it's the socio-techno divide!' Proceedings of the 12th European Conference on Information Systems, Turku, Finland, 2004.

Savage, G., Nix, T., Whitehead, C. \& Blair, J. 1991. 'Strategies for assessing and managing organisational stakeholders', Academy of Management Executive, 5(2):6175 .

Scholl, H. 2001. 'Applying stakeholder theory to egovernment: Benefits and limits'. Proceedings of the IFIP Conference on Towards the E-Society: E-Commerce, EBusiness, E-Government, Deventer, Netherlands.

Scholl, H. 2003. 'E-government: A special case of ICTenabled business process change'. Proceedings of the 36th Annual Hawaii International Conference on Systems Sciences, Hawaii, 6-9 Jan 2003.

Valentine, S. 2004. 'E-powering the people: South Africa's Smart Cape Access Project'. [online] URL:http://www.clir.org/pubs/reports/pub125/pub125.pdf. Accessed July 15, 2008.

Warschauer, M. 2003. Technology and social inclusion: Rethinking the digital divide. Cambridge; Massachusetts Institute of Technology Press

Zhang, J., Dawes, S. \& Sarkis, J. 2004. 'Exploring stakeholders' expectations of the benefits and barriers of egovernment knowledge sharing', The Journal of Enterprise Information Management, 18(5):548-567. 